\title{
P107 Endothelial Dysfunction Associated with Arterial Stiffness in Postmenopausal Women with Obesity
}

\author{
Patricia Lizette Ramírez Soltero ${ }^{1, *}$, Leonel García Benavides ${ }^{2}$, Marycruz Barocio Pantoja ${ }^{1}$, \\ Brandon Giovanni Illescas Vidrio ${ }^{1}$, David Cardona Müller ${ }^{1}$, Ernesto Germán Cardona Muñoz ${ }^{1}$, \\ Sylvia Elena Totsuka Sutto ${ }^{1}$
}

${ }^{1}$ Department of Physiology, Arterial Stiffness Laboratory, Experimental Therapeutic and Clinic Institute, Health Sciences University Center, University of Guadalajara, Guadalajara, Mexico

${ }^{2}$ Department of Physiology, University Center Tonalá, University of Guadalajara, Guadalajara, Mexico

\begin{abstract}
Background: Endothelial dysfunction (ED) represents an initial step of "vascular failure" [1]; several factors affect the functionality of the endothelium. Obesity [2] and estrogen deficiency [3] are independently associated with this. The early detection of ED is essential to intervene and prevent its progression. One of the most promising methods to assess vascular endothelial function is the measurement of endothelium- dependent flow-mediated vasodilation (FMD) [1]. Similarly, pulse wave velocity (PWV) is considered as a predictive value for the stratification of vascular risk [4], however, progression between endothelial events and arterial stiffness continues to be examined.
\end{abstract}

Objective: To evaluate the association between endothelial dysfunction and arterial stiffness in postmenopausal women with obesity.

Methods: Descriptive study of 19 postmenopausal women with grade I and II obesity, without associated comorbidities. Participants were classified into one of two groups: with ED (FMD < 6\%) or non-ED (FMD > 6\%). The hemodynamic metabolic, hormonal and arterial stiffness parameters were evaluated.

Results: The group with ED $(n=10)$ compared to the non-ED group $(n=9)$ presented age $57.30 \pm 4.80$ vs $52.40 \pm 5.70$ years ( $p=$ NS); BMI $34.75 \pm 2.06$ vs $33.06 \pm 2.51 \mathrm{~kg} / \mathrm{m}^{2}$ ( $p=\mathrm{NS}$ ). Statically significant findings include: FSH $35.43 \pm 11.04$ vs 55.19 $\pm 19.27 \mathrm{mUI} / \mathrm{ml}(p=0.018)$; PWV $9.18 \pm 1.84$ vs $7.52 \pm 1.26 \mathrm{~m} / \mathrm{s}(p=0.041) ;$ central SBP $135 \pm 15.90$ vs $120 \pm 18.2 \mathrm{mmHg}$ $(p=0.041)$. We also measure estradiol, QIMT, SBP, DBP, PP, AIx, LDL-C, HDL-C and triglycerides, no significant differences were observed.

Conclusion: We can conclude that in the group with endothelial dysfunction the PWV and the cSBP are higher with a significant difference.

\section{REFERENCES}

[1] Inoue T, Matsuoka H, Higashi Y, Ueda S, Sata M, Shimada KE, et al. Flow-mediated vasodilation as a diagnostic modality for vascular failure. Hypertens Res 2008;31:2105-13.

[2] Engin A. Endothelial dysfunction in obesity. Adv Exp Med Biol 2017;960:345-79.

[3] Somani YB, Pawelczyk JA, De Souza MJ, Kris-Etherton PM, Proctor DN. Aging women and their endothelium: Probing the relative role of estrogen on vasodilator function. Am J Physiol Heart Circ Physiol 2019;317:H395-H404.

[4] Engelen L, Bossuyt J, Ferreira I, van Bortel LM, Reesink KD, Segers P, et al. Reference values for local arterial stiffness. Part A: carotid artery. J Hypertens 2015;33:1981-96.

(C) 2019 Association for Research into Arterial Structure and Physiology. Publishing services by Atlantis Press International B.V. This is an open access article distributed under the CC BY-NC 4.0 license (http://creativecommons.org/licenses/by-nc/4.0/). 